\title{
Exigências de uma semeadora-adubadora de precisão variando a velocidade e a condição da superfície do solo
}

\author{
Seeder requiriment changing the speed and soil surface condition
}

\author{
Carlos Eduardo Angeli Furlani ${ }^{1}$ Afonso Lopes ${ }^{1}$ \\ Rouverson Pereira da Silva ${ }^{1}$ Gustavo Naves dos Reis ${ }^{2}$
}

\section{NOTA}

\section{RESUMO}

O objetivo do trabalho foi avaliar o desempenho de um conjunto trator-semeadora-adubadora de quatro linhas, variando as marchas do trator e preparo do solo. A semeadura foi realizada em Latossolo Vermelho Eutroférrico. Os tratamentos foram: preparo do solo (convencional, reduzido e plantio direto) e marchas do trator $\left(5,9 \mathrm{~km} \mathrm{~h}^{-1}\right.$ e $\left.7,0 \mathrm{~km} h^{-1}\right)$, em delineamento de blocos casualizados em fatorial $3 \times 2$ com quatro repetições. Foram analisadas: velocidade de deslocamento, capacidade de campo operacional, consumo de combustível horário e por área, patinagem, força de tração e potência na barra. A velocidade, a patinagem e os consumos de combustível horário e por área foram maiores para a marcha $M 2\left(7,0 \mathrm{~km} \mathrm{~h}^{-1}\right)$ e o conjunto trabalhando em área cujo preparo do solo foi realizado com escarificador apresentou maiores valores para os consumos de combustível horário e por área e também menor velocidade operacional.

Palavras-chave: capacidade de campo, desempenho, consumo de combustível.

\section{ABSTRACT}

The objective of the work was to evaluate the performance of a set tractor-four lines seeder, when and operating at different tractor gears and soil tillage, on corn crop planting. The sowing was carried out through in darkred Oxisoil, eutrophic. The treatments designs had been composites of tillage systems (conventional, reduced and notillage) and marches of the set tractor-seeder $(5.9$ and $7.0 \mathrm{~km}$ $\left.h^{-1}\right)$. The experimental delineation was in a randomized blocks design in factorial array of $3 \times 2$ with 4 replications. The analyzed variables had been: forward speed, field operational capacity, hourly and area fuel consumption, wheels lip, draft force and drawbar power. The speed, the wheels lip and fuel consumption had been higher for gear M2 (7.0km. $\left.h^{-1}\right)$ when operating in soil prepared by reduced soil tillage also presented greater values fuel consumption and lower speed of sowing.

Key words: field capacity, performance, fuel consumption.

Os métodos de preparo podem ser classificados como: convencional, caracterizado normalmente por uma aração e duas gradagens leves; reduzido, realizado por meio do uso de escarificadores e plantio direto, com mobilização do solo somente nas linhas de semeadura (GAMERO et al., 1997). No Brasil, a semeadura direta tem se expandido devido às suas vantagens nos aspectos econômicos e ambientais por ser um método que visa a maior conservação do solo e diminuição do tráfego de máquinas agrícolas. O consumo de combustível pode ser diretamente afetado pelo sistema de preparo utilizado e neste sentido, FURLANI (2000), avaliando uma semeadora de 6 linhas para feijão obteve maior consumo de combustível por área trabalhada em solo escarificado $\left(9,3 \mathrm{~L} \mathrm{ha}^{-1}\right)$, seguido pelo preparo convencional $\left(7,6 \mathrm{~L} \mathrm{ha}^{-1}\right)$ e plantio direto $\left(7,1 \mathrm{~L} \mathrm{ha}^{-1}\right)$, para a capacidade de campo efetiva

${ }^{1}$ Departamento de Engenharia Rural, Universidade Estadual Paulista, 14884-900, Jaboticabal, SP, Brasil. Fone: 16-3209-2637.

E-mail: furlani@fcav.unesp.br.

${ }^{2}$ Curso de Pós-graduação em Ciência do Solo, Unesp-Jaboticabal, SP, Brasil. 
encontrou valores de $1,57,1,50$ e $1,40 \mathrm{ha}^{-1}$ para plantio direto, convencional e solo escarificado, respectivamente.

A velocidade de semeadura é um dos parâmetros que mais influencia o desempenho de semeadoras, sendo a distribuição longitudinal de sementes afetada pela velocidade de deslocamento, que, por sua vez, influencia a produtividade da cultura (DELAFOSSE, 1986). Entretanto SILVA (2000) conclui que a uniformidade de distribuição de sementes não foi influenciada pela velocidade na implantação de culturas de milho e soja. O objetivo do trabalho foi avaliar as exigências de uma semeadora-adubadora de precisão, em função de duas marchas do trator e da superfície do solo.

O experimento foi conduzido na FEPP/ Unesp/Jaboticabal-SP, localizada nas coordenadas geográficas $21^{\circ} 14^{\prime}$ Sul e $48^{\circ} 16^{\prime}$ Oeste, com altitude média de 559m, em Latossolo Vermelho Eutroférrico, A moderado e textura argilosa (EMBRAPA, 1999). A semeadura foi realizada em delineamento experimental de blocos casualizados (fatorial $3 \times 2$ ), com 4 repetições, em parcelas de $25 \mathrm{~m}$ de comprimento. Os tratamentos constituíram de três sistemas de preparo de solo: plantio direto; convencional (uma aração e duas gradagens niveladoras) e escarificação. As duas marchas utilizadas na semeadura proporcionaram velocidades teóricas de 5,9 e 7,0 $\mathrm{km} \mathrm{h}^{-1}$, com o motor do trator iniciando a operação em rotação máxima.

No preparo do solo, foram utilizados um arado reversível montado, com três discos de $660 \mathrm{~mm}$ de diâmetro, largura de corte de $0,9 \mathrm{~m}$ e profundidade de $0,25 \mathrm{~m}$; uma grade niveladora de arrasto com 32 discos lisos de $458 \mathrm{~mm}$ de diâmetro e largura de trabalho de $2,77 \mathrm{~m}$ e um escarificador de 7 hastes parabólicas, conjugado com rolo destorroador e discos de corte, com espaçamento de $30 \mathrm{~cm}$ entre hastes, largura de trabalho de $2,10 \mathrm{~m}$ e profundidade de $0,30 \mathrm{~m}$.

A semeadora-adubadora de precisão utilizada foi da marca Marchesan, modelo Cop Suprema equipada com 4 linhas espaçadas de $0,90 \mathrm{~m}$, largura útil de $3,6 \mathrm{~m}$, com profundidade média de semeadura de $0,05 \mathrm{~m}$. Para o sistema plantio direto, foi utilizado sulcador de adubo tipo haste (facão) e, para os sistemas convencional e reduzido, discos duplos defasados. A capacidade da semeadora-adubadora é de $1310 \mathrm{~kg}$ de adubo e $200 \mathrm{~kg}$ de semente e, durante o experimento, os depósitos foram mantidos com meia carga.

Utilizou-se um trator Valtra BM-100,4x2 TDA com $73,6 \mathrm{~kW}(100 \mathrm{cv})$ de potência no motor para tracionar a semeadora-adubadora. O trator encontrava-se com pneus dianteiros 14.9-24R1 e traseiros 23.1-26R1 e massa total em ordem de marcha com lastro de $5.400 \mathrm{~kg}$.
Para a medição da velocidade real de deslocamento, utilizou-se uma unidade de radar localizada na lateral direita do trator. A capacidade de campo operacional foi determinada por meio do tempo de percurso na parcela e a largura útil de trabalho da semeadora, considerando-se segundo a ASAE (1997) uma eficiência de campo de $65 \%$.

O consumo horário de combustível foi obtido por meio de equipamento desenvolvido por LOPES et al. (2003). O consumo por área foi obtido pela relação consumo hora/capacidade de campo operacional. A patinagem médias dos rodados do trator foi obtida por meio de um gerador de impulsos modelo GIDP-60BD.

É possível observar que a patinagem do trator durante a operação de semeadura foi afetada somente pela marcha, enquanto a capacidade de campo operacional, o consumo de combustível horário e por área, foram afetados pelos demais fatores também avaliados (Tabela 1), sendo que a interação (M x P) foi significativa somente para a capacidade de campo, tornando-se necessário o desdobramento (Tabela 1).

A capacidade operacional da semeadora foi maior quando o trator trabalhou na marcha M2 em solo preparado pelo método convencional e plantio direto, porém, na escarificação não houve diferença. Quando se analisou as marchas individualmente nos preparos, observou-se que M1 não apresentou diferença significativa, enquanto, em M2 a semeadura realizada em preparo com escarificador resultou em menor capacidade operacional. Na semeadura realizada em preparo com escarificador, mesmo variando a marcha do trator $\mathrm{e}$ obtendo-se maior velocidade, não ocorreu aumento da capacidade operacional. Isso pode ser explicado pelo fato de que, neste tipo de preparo, o solo se encontrava mais solto, fazendo com que ocorresse maior patinagem, embora não tenha ocorrido diferença significativa para esta variável, resultados semelhantes foram encontrados por FURLANI (2000). Com relação ao consumo de combustível horário e por área na operação de semeadura, a marcha M2 do trator e o preparo com escarificador resultaram em maiores valores.

Observa-se que a potência e a força de tração na barra na operação de semeadura não foram influenciadas pelos fatores marcha do trator e preparo do solo (Tabela 2). Observa-se também que houve uma menor queda na rotação do motor do trator para a semeadura em plantio direto, quando comparado ao solo escarificado, decorrente da maior exigência de força na barra de tração, embora não tenha havido diferença significativa. Ainda em solo 
Tabela 1 - Síntese da análise de variância e do teste de médias para capacidade de campo operacional, consumo de combustível horário e por área e patinagem.

\begin{tabular}{|c|c|c|c|c|}
\hline Fatores & $\begin{array}{l}\text { Capacidade de campo } \\
\text { operacional }\left(\mathrm{ha} \mathrm{h}^{-1}\right)\end{array}$ & $\begin{array}{l}\text { Consumo horário de } \\
\text { combustível }\left(\mathrm{L} \mathrm{h}^{-1}\right)\end{array}$ & $\begin{array}{c}\text { Consumo de combustível } \\
\text { por área }\left(\mathrm{L} \mathrm{ha}^{-1}\right)\end{array}$ & Patinagem $(\%)$ \\
\hline \multicolumn{5}{|l|}{ MARCHA (M) } \\
\hline $\mathrm{M}_{1}\left(5,9 \mathrm{~km} \mathrm{~h}^{-1}\right)$ & 1,49 & $12,88 \mathrm{a}$ & $5,66 \mathrm{a}$ & $5,1 \mathrm{a}$ \\
\hline $\mathrm{M}_{2}\left(7,0 \mathrm{~km} \mathrm{~h}^{-1}\right)$ & 1,64 & $15,23 \mathrm{~b}$ & $6,13 \mathrm{~b}$ & $10,1 \mathrm{~b}$ \\
\hline \multicolumn{5}{|l|}{ PREPARO (P) } \\
\hline Convencional & 1,58 & $13,25 \mathrm{a}$ & $5,48 \mathrm{a}$ & $6,7 \mathrm{a}$ \\
\hline Direto & 1,59 & $13,46 \mathrm{a}$ & $5,52 \mathrm{a}$ & $6,1 \mathrm{a}$ \\
\hline Escarificador & 1,51 & $15,44 \mathrm{~b}$ & $6,70 \mathrm{~b}$ & $10,1 \mathrm{a}$ \\
\hline \multicolumn{5}{|l|}{ TESTE F } \\
\hline $\mathrm{M}$ & $63,68 * *$ & $56,55 * *$ & $6,88 *$ & $11,79 *$ \\
\hline $\mathrm{P}$ & $7,35 * *$ & $19,87 * *$ & $19,85 * *$ & $3,01 \mathrm{NS}$ \\
\hline $\mathrm{MxP}$ & $3,81 *$ & $1,18 \mathrm{NS}$ & $1,75 \mathrm{NS}$ & $0,69 \mathrm{NS}$ \\
\hline $\mathrm{CV} \%$ & 2,93 & 5,45 & 7,43 & 46,19 \\
\hline \multicolumn{5}{|c|}{ Interação entre velocidade e preparo do solo para a variável capacidade de campo operacional $\left(\mathrm{ha} \mathrm{h}^{-1}\right)$} \\
\hline \multirow{2}{*}{ Marcha } & \multicolumn{4}{|c|}{ Preparo do solo } \\
\hline & Convencional & \multicolumn{2}{|l|}{ Direto } & Escarificador \\
\hline $\mathrm{M}_{1}$ & $1,47 \mathrm{aA}$ & \multicolumn{2}{|l|}{$1,53 \mathrm{aA}$} & $1,46 \mathrm{aA}$ \\
\hline $\mathrm{M}_{2}$ & $1,69 \mathrm{bA}$ & \multicolumn{2}{|l|}{$1,66 \mathrm{bA}$} & $1,56 \mathrm{aB}$ \\
\hline
\end{tabular}

Em cada coluna, para cada fator, médias seguidas de mesma letra minúscula, e em cada linha, médias seguidas de mesma letra maiúscula não diferem entre si pelo Teste de Tukey a $5 \%$ de probabilidade de erro.

preparado com escarificador, a velocidade de semeadura foi menor nas duas marchas avaliadas, em conseqüência da maior patinagem.

A velocidade, a patinagem e os consumos de combustível horário e por área foram maiores quando se utilizou a marcha M2 $\left(7,0 \mathrm{~km} \mathrm{~h}^{-1}\right)$, durante a operação de semeadura. A semeadura em solo preparado com escarificador apresentou maiores consumos de combustível horário e por área superior ao obtido para a mesma operação em plantio direto e em preparo convencional. A velocidade operacional do trator também foi menor, quando o solo foi preparado desta forma, independente da marcha utilizada.

Tabela 2 - Síntese da análise de variância e do teste de médias para velocidade, potência na barra de tração, força de tração e rotação do motor.

\begin{tabular}{|c|c|c|c|c|}
\hline Fatores & Velocidade $\left(\mathrm{km} \mathrm{h}^{-1}\right)$ & Potência na barra de tração $(\mathrm{kW})$ & Força de tração $(\mathrm{N})$ & Rotação do motor (rpm) \\
\hline \multicolumn{5}{|l|}{ MARCHA (M) } \\
\hline $\mathrm{M}_{1}\left(5,9 \mathrm{~km} \mathrm{~h}^{-1}\right)$ & $6,33 \mathrm{a}$ & $23,80 \mathrm{a}$ & $13.548 \mathrm{a}$ & $2.088 \mathrm{a}$ \\
\hline $\mathrm{M}_{2}\left(7,0 \mathrm{~km} \mathrm{~h}^{-1}\right)$ & $6,94 \mathrm{~b}$ & $26,57 \mathrm{a}$ & $13.804 \mathrm{a}$ & $2.089 \mathrm{a}$ \\
\hline \multicolumn{5}{|l|}{ PREPARO (P) } \\
\hline Convencional & $6,71 \mathrm{a}$ & $24,00 \mathrm{a}$ & $12.810 \mathrm{a}$ & $2.098 \mathrm{ab}$ \\
\hline Direto & $6,78 \mathrm{a}$ & 25,71 a & $13.684 \mathrm{a}$ & $2.105 \mathrm{a}$ \\
\hline Escarificador & $6,41 \mathrm{~b}$ & $25,84 \mathrm{a}$ & $14.535 \mathrm{a}$ & $2.063 \mathrm{~b}$ \\
\hline \multicolumn{5}{|l|}{ TESTE F } \\
\hline M & $76,62 * *$ & $4,42 \mathrm{NS}$ & $0,13 \mathrm{NS}$ & $0,01 \mathrm{NS}$ \\
\hline $\mathrm{P}$ & $10,09 * *$ & $0,81 \mathrm{NS}$ & $2,01 \mathrm{NS}$ & $4,09 *$ \\
\hline $\mathrm{MxP}$ & $2,70 \mathrm{NS}$ & $1,51 \mathrm{NS}$ & $0,96 \mathrm{NS}$ & $2,14 \mathrm{NS}$ \\
\hline $\mathrm{CV} \%$ & 2,60 & 12,80 & 12,60 & 1,53 \\
\hline
\end{tabular}

Em cada coluna, para cada fator, médias seguidas de mesmas letras minúsculas não diferem entre si, pelo Teste de Tukey a $5 \%$ de probabilidade de erro.

NS: não significativo $(\mathrm{P}>0,05)$, *: significativo $(\mathrm{P}<0,05)$, **: significativo $(\mathrm{P}<0,01), \mathrm{C} . \mathrm{V}$.: coeficiente de variação

Ciência Rural, v.35, n.4, jul-ago, 2005. 


\section{REFERÊNCIAS}

AMERICAN SOCIETY OF AGRICULTURAL ENGINEERS

Agricultural machinery management data. In ASAE standards 1997: standards engineering practices data. San Joseph, 1997. p.363-70.

DELAFOSSE, R.M. Máquinas sembradoras de grano gruesso. Santiago : FAO, 1986. 48p.

EMPRESA BRASILEIRA DE PESQUISA AGROPECUÁRIA Serviço nacional de levantamento e conservação do solo. Manual de métodos de análise de solo. Rio de Janeiro: EMBRAPA. 1999. n.p.

FURLANI. C.E.A. Efeito do preparo do solo e do manejo da cobertura de inverno na produtividade da cultura do feijoeiro (Phaseolus vulgaris L.). 2000. 218f. Tese
(Doutorado em Agronomia) - Curso de Pós-graduação em Energia na Agricultura, Universidade Estadual Paulista.

GAMERO, C.A. et al. Prepara os implementos que está chegando a hora. A Granja, n.585, p.14-231, 1997.

LOPES, A. et al. Desenvolvimento de um protótipo para medição do consumo de combustível em tratores. Revista Brasileira de Agroinformática, Lavras, v.5, n.1, p.24-31, 2003.

SILVA, S.L. Avaliação de semeadoras para plantio direto: demanda energética, distribuição longitudinal e profundidade de deposição de sementes em diferentes velocidades de deslocamento. 2000. 123f. Tese (Doutorado em Agronomia) - Curso de Pós-graduação em Energia na Agricultura, Universidade Estadual Paulista. 